\title{
Toward a Renewal of Patient Care: Insights From Viktor Frankl, MD, PhD
}

Joseph R. Laracy, SM, STL; Michael D. Kelly, DO

\footnotetext{
From the Department of Mathematics and Computer Science and the Immaculate Conception Seminary School of Theology (Fr Laracy) and the College of Health and Medical Sciences (Dr Kelly) at Seton Hall University in South Orange, New Jersey.

Financial Disclosures: None reported.

Support: None reported.

Address correspondence to Fr Joseph R. Laracy, SM, STL,

Seton Hall University, 400 S Orange Ave South Orange, NJ 07079-2646. Email: joseph.laracy@shu.edu Submitted July 27, 2017; revision received August 23, 2017; accepted August 27, 2017.
}

$\mathrm{I}$ their April 2017 article "Can the Humanities Humanize Health Care?", Baltonado and Cymet raise a number of fascinating issues with regard to osteopathic medical education and clinical practice. They begin by mentioning that some recent studies have shown concrete benefits of exposing medical students more intentionally to topics in literature, philosophy, language, religion, art, and music, as they may relate to the theory and practice of medicine. Next, the authors ask 2 excellent questions: "Can [the] study of the humanities reinforce the osteopathic philosophy that emphasizes care for the whole person: body, mind, and spirit [emphasis added]? How do we develop a better appreciation or understanding of our patients?" We suggest that the writings of the distinguished Austrian professor of neurology and psychiatry, Viktor Frankl, $\mathrm{MD}, \mathrm{PhD}$, might provide an approach toward a renewal of patient care, viewing humans in a more holistic way: body, mind, and spirit.

Frankl was born in 1905 in Vienna, Austria. As a young man, he was drawn to medicine, philosophy, and psychology. Frankl attended the University of Vienna, where he earned his MD degree, and then pursued a residency in neurology and psychiatry. (He would later earn a doctorate in philosophy in 1948.) Sadly, because of his Jewish heritage, he, his wife, and his parents were arrested by the Nazis in 1942. Until his liberation by US soldiers in April 1945, he experienced the darkest side of fallen humanity in the death camps. Tragically, his parents and wife did not survive.

Frankl's profound experience of personal suffering, as well as his service as a physician to his fellow prisoners, confirmed his hypothesis about the most fundamental drive in humans. Although he was well aware of the important contributions of Sigmund Freud and Alfred Adler, Frankl disagreed fundamentally with their paradigms.
According to Freud (First Viennese School of Psychotherapy), the drive for pleasure, particularly sexual pleasure, was the dominant force in the human psyche. Although Adler was initially a collaborator of Freud, he went in a different direction. Influenced by the philosophy of Friedrich Nietzsche, Adler suggested that the drive for power was the key to understanding man (Second Viennese School of Psychotherapy).

By contrast, Frankl's hypothesis was that the strongest force in a human was the will to meaning. In his view, meaning is something that is discovered, rather than produced, and can be encountered through experiential, creative, or attitudinal values. Frankl described the 3 types of values in this way:

Values which are realized in creative action we should like to call "creative" values. In addition to these, there are values which are realized in experience: "experiential values." These latter are realized in receptivity toward the world-for example, in surrender to the beauty of nature or art. ... The third group of values lies precisely in a man's attitude toward the limiting factors upon his life. His very response to the restraints upon his potentialities provides him with a new realm of values which surely belong among the highest values. ... These values we will call attitudinal values. What is significant is the person's attitude toward an unalterable fate. The opportunity to realize such attitudinal values is therefore always present whenever a person finds himself confronted by a destiny toward which he can only act by acceptance. The way in which he accepts, the way in which he bears his cross, what courage he manifests in suffering, what dignity he displays in doom and disaster, is the measure of his human fulfillment. ${ }^{2(p p 43-44)}$

Although Frankl and his fellow prisoners were effectively deprived of the ability to realize the desires for pleasure or power during their confinement, the Nazis were incapable of taking away all 
sources of meaning. Prisoners were still able to discover meaning in a person to love (experiential), a cause to serve (creative), or a courageous stance toward unavoidable suffering (attitudinal). In many cases, Frankl witnessed that those prisoners who lost any sense of meaning in their life would often quickly develop a somatic illness, such as typhus. He found that "the sudden loss of hope and courage can have a deadly effect."3(p75)

Andrew Taylor Still, MD, DO, made a major contribution to medical theory and practice in the late $1800 \mathrm{~s}$ and early 1900 s by breaking out of the prevailing paradigm of viewing patients simply as a collection of symptoms to which various treatments, such as bloodletting and mercury, should be applied. Still distinguished himself by taking the time to get to know his patients and addressing the whole person in the quest to discover the cause of their poor health. ${ }^{4}$ Like Still, ${ }^{5}$ Frankl insisted that man must be viewed holistically: body, mind, and spirit. ${ }^{6}$ Frankl described 3 factors that categorize human existence: spirituality, freedom, and responsibility. He asserted:

The spirituality of man is a thing-in-itself. It cannot be explained by something not spiritual; it is irreducible. It may be conditioned by something without being caused by it. Normal bodily functions affect the unfolding of the spiritual life, but they do not cause it or produce it. ${ }^{2(\text { pxxiv) }}$

"Freedom" refers to some degree of independence from instincts, inherited dispositions, and the environment. According to Frankl's anthropology,

Freedom, however, is not the last word. Freedom is only part of the story and half of the truth. Freedom is but the negative aspect of the whole phenomenon whose positive aspect is responsibleness. In fact, freedom is in danger of degenerating into mere arbitrariness unless it is lived in terms of responsibleness. ${ }^{3(\mathrm{p} 132)}$

He went on to suggest that the Statue of Liberty on the East Coast be complemented by a "Statue of Responsibility" on the West Coast.

Frankl's extensive clinical work and scholarly research led him to develop what is often referred to as the Third Viennese School of Psychotherapy, a type of existential analysis referred to as logotherapy (from the Greek logos: meaning or reason). He realized that in addition to the traditional classification of mental disorders, such as endogenous psychoses (mental disorders with a biological cause, such as major depression), psychosomatic illnesses (physical illnesses triggered by psychological factors but not caused by them, such as asthma), organ neuroses (disorders involving physical symptoms that appear to be caused by a medical condition but are in fact caused by psychological factors, such as conversion disorder), psychogenic neuroses (mental disorders arising from psychological causes, such as a tic disorder in reaction to stress), and so on, a distinct category of neuroses must be considered: noogenic (from the Greek nous: thought or understanding) neuroses. These neuroses are mental disorders arising from spiritual or existential causes, such as adjustment disorder with depressive mood in response to a divorce.

Noogenic neuroses may arise in a person when existential frustration is not properly managed. Frankl discovered that when the existential or spiritual character of a crisis was not addressed (eg, it was ignored or repressed), mental health typically declined with symptoms of aggression, addiction, depression, anxiety, etc. A logotherapeutic approach to noogenic neuroses is based on 3 pillars: acknowledging the freedom of the will (ie, contra determinism), the will to meaning (ie, the primary life force, contra Freud and Adler), and the meaning of life (ie, a specific mission in life for every person). ${ }^{7}$ Frankl joked that a physician who fails to acknowledge and respect the existential or spiritual dimension of the patient is no different than a veterinarian:

Homo patiens draws out the medicus humanus, that is, the suffering human draws out the human in the physician. The doctor who is not also human, but is only scientific, is able to amputate a leg with the help of science; but the help of science alone does not allow him or her to prevent the amputee, or intended amputee, from committing suicide .... It was not by accident that the founder of 
the General Hospital in Vienna, Kaiser Joseph II, directed that a tablet be hung over the door with the inscription: Saluti et solatio agrorum - that is, dedicated not only to the healing, but also to the consolation of the ill. ${ }^{6(\mathrm{p} 222)}$

Frankl's approach to patient care-viewing the person in his or her somatic, psychic, and noetic dimensions - ought not be limited to physicians specializing in psychiatry. He is clear that when he uses the German term geist, which is often translated to spirit from the Latin spiritus (pneuma in Greek), that it is without specific religious reference. In a logotherapeutic paradigm, "spirit" refers to the specifically human dimension of the person. In other words, even the most highly evolved animal cannot realize values of courage or hope in the face of suffering, such as physical pain. Whether it is the dermatologist treating a patient with severe facial disfigurement, the neurologist helping a person with a degenerative disorder of the central nervous system, the orthopedist amputating a diseased limb, or the primary care physician treating an elderly patient with chronic pain, the physician is called to help those who can no longer realize creative or experiential values. "Life has meaning up to the very last breath,"2(pxix) wrote Frankl. Therefore, the possibility always remains for physicians to help patients realize values through the attitude they take toward unavoidable suffering.

Baltonado and Cymet $^{1}$ discuss how the study of philosophy, religion, and the arts can provide "powerful tools to individualize care for the patient and to provide self-care and support to physicians in a stressful profession." They further state, "To maximize a patient's health, physicians must look beyond the science and see the individual." Given these substantial benefits, it might be helpful for osteopathic faculty members to explore ways of integrating the writings of Frankl into their curriculum. A selection of readings by Frankl could be discussed in a seminar format, perhaps by a team of a psychiatry professor and a hospital chaplain. This setting would provide an ideal space for osteopathic medical students to engage Frankl's thought; acknowledge the somatic, mental, and existential issues of patients; and thus learn to provide the level of care that Still envisioned. (doi:10.7556/jaoa.2018.074)

\section{References}

1. Baltonado J, Cymet T. Can the humanities humanize health care? J Am Osteopath Assoc. 2017;117(4):273-275. doi:10.7556/jaoa.2017.046

2. FrankI VE. The Doctor and the Soul: From Psychotherapy to Logotherapy. Winton R, Winton C, trans. New York, NY: Vintage Books; 1986.

3. FrankI VE. Man's Search for Meaning. Lasch I, trans. Boston, MA: Beacon Press; 2006.

4. Hubbard E. Andrew Taylor Still: Being a Little Journey to the Home of the Founder of Osteopathy. London, UK: Forgotten Books; 2015.

5. Still AT. Philosophy of Osteopathy. Kirksville, MO: published by the authors; 1899. http://www.gutenberg.org/files/25864/25864-h/25864-h. htm. Accessed March 13, 2018.

6. Frankl VE. On the Theory and Therapy of Mental Disorders: An Introduction to Logotherapy and Existential Analysis. Dubois JM, trans. New York, NY: Brunner-Routledge; 2004.

7. Frankl VE. The Will to Meaning: Foundations and Applications of Logotherapy. New York, NY: Penguin Books; 2014.

๑ 2018 American Osteopathic Association 